\title{
ASSESSMENT OF REQUIRED TORQUE AND POWER BYBIG SQUARE BALER DURING THE WRAPPING AND BALING PROCESS
}

\author{
Simone Pascuzzi ${ }^{1}$, Arrigo Salvatore Guerrieri ${ }^{2}$, Francesco Vicino ${ }^{1}$, Francesco Santoro ${ }^{1}$ \\ ${ }^{1}$ University of Bari Aldo Moro, Italy; ${ }^{2}$ University of Tuscia, Italy \\ simone.pascuzzi@uniba.it, guerrieriarrigo@yahoo.it,f.vicino92@gmail.com, \\ francesco.santoro@uniba.it
}

\begin{abstract}
The big square baler is an operating machine that performs the harvesting of hay and crop residues (straw) and the wrapping and baling process of big prismatic bales. The main operating organs of the machine are: i) the harvesting head; ii) the feeder; iii) the compression chamber and iv) the binding apparatus. The required power by the HD1270 big square baler, manufactured by Cicoria in Palazzo San Gervasio (near Potenza, Italy) has been studied. This big baler HD1270 is equipped with specially designed and manufactured devices aimed at reducing the costs of wrapping and baling. Practically these devices are the "Leverage Piston System", the "Top Feeding System" and the "Controlled Binding System", which manage, respectively, the motion of the piston, the feeding of the product and the binding operations. According to the manufacturer's technical specifications, these devices allow minimum required power from the tractor down to only $60 \mathrm{~kW}$. Using an ad hoc high precision torque meter and tachometer, mounted between the tractor power take-off (PTO) and the cardan shaft connecting the HD 1270 big baler, the required torque values and power during the straw wrapping and baling process were measured and recorded. The tests were repeated considering different operating conditions. The obtained results were statistically evaluated in the time domain and clearly showed that the effective required power complies with technical specifications. The variability in stress could induce fatigue phenomena in the components that make up the piston motion transmission chain, with a reduction in their useful life.
\end{abstract}

Keywords: big square baler, power take off, torque meter, straw, tractor, statistical analysis.

\section{Introduction}

The mechanization of the production chain of bales, as well as their manipulation, transport and flexibility are of very interest in the agricultural sector [1-3]. Bales remarkably reduce post-harvest biomass losses, while increasing the storage capacity, giving farmers more long-term flexibility in zootechnic feeding $[4 ; 5]$.

As it is known, the balers harvest loose hay or straw, compact it into bales, and bind them through twine [6;7]. All these operations are carried out in accordance with the in force operators' safety requirements [8-10]. Basically, there are three types of balers on the market, able to manufacture, respectively, small rectangular bales, big round bales and big square bales [1]. These last balers produce bales from 120 to $600 \mathrm{~kg}$ in straw or from 200 to $900 \mathrm{~kg}$ in hay [2]. Within this type of machine, a novel one is the big square baler HD 1270, built by "Cicoria Square Bales" manufacturer (hereinafter Cicoria's machine), placed in Southern Italy, whose main feature is the relevant reduction of residual soil and impurities inside bales $[11 ; 12]$.

The main operating organs of this machine are: i) the harvesting head; ii) the feeder; iii) the compression chamber and iv) the binding apparatus. This big baler HD1270 is equipped with specially designed and manufactured devices aimed at reducing the costs of wrapping and baling. In particular, these devices are represented by the following [11]:

- the "Leverage Piston System", which is a piston mechanism based on a balance levers system, capable of transmitting a thrust of about $18 \cdot 10^{7} \mathrm{~N}$ into the compression chamber by requiring just $60 \mathrm{~kW}$ at the PTO (Power Take-Off) of the tractor;

- the "Top Feeding System", formed by two synchronized rotors able to transfer the product in a channel of $3.3 \mathrm{~m}$ length, which feeds the compression chamber from the top;

- the "Controlled Binding System", capable to control the tension of the twines and the stress on the knotters.

According to the manufacturer's technical specifications, the Cicoria's machine allows minimum required power from the tractor down to only $60 \mathrm{~kW}[13 ; 14]$. Taking in mind this last feature of the machine, the aim of this paper is to evaluate by means experimental test the actual required power by the big square baler HD 1270 during the operative conditions. 


\section{Materials and methods}

Experimental tests were carried out on July 23, 2020, using the large square baler Cicoria HD 1270T, trailed by the tractor New Holland 6090 (Fig. 1). The baling process has been carried out harvesting loose straw, which laid on the soil for about two weeks, characterized by dry days and great sunshine. The bales produced had sizes (width $\mathrm{x}$ height $\mathrm{x}$ length, $\mathrm{cm}$ ) 120x70x240 and average density of $180 \mathrm{~kg} \cdot \mathrm{m}^{-3}$.

The main technical features of the Cicoria's machine were: baler weight, $7210 \mathrm{~kg}$; pick-up working width, $2.20 \mathrm{~m}$; binding system controlled by 6 knotters; leverage piston system, 48 piston stroke $\mathrm{min}^{-1}$; feeding channel volume, $0.92 \mathrm{~m}^{3}$; feeding channel length, $3.30 \mathrm{~m}$; tractor requirement minimum power at PTO, $60 \mathrm{~kW}$ at PTO speed of $104.72 \mathrm{rad} \cdot \mathrm{s}^{-1}$.

The main technical characteristics of the tractor New Holland 6090 were: rated power, $121 \mathrm{~kW}$ at $230.38 \mathrm{rad} \cdot \mathrm{s}^{-1}$; max torque, $710 \mathrm{Nm}$ at $146.61 \mathrm{rad} \cdot \mathrm{s}^{-1}$.

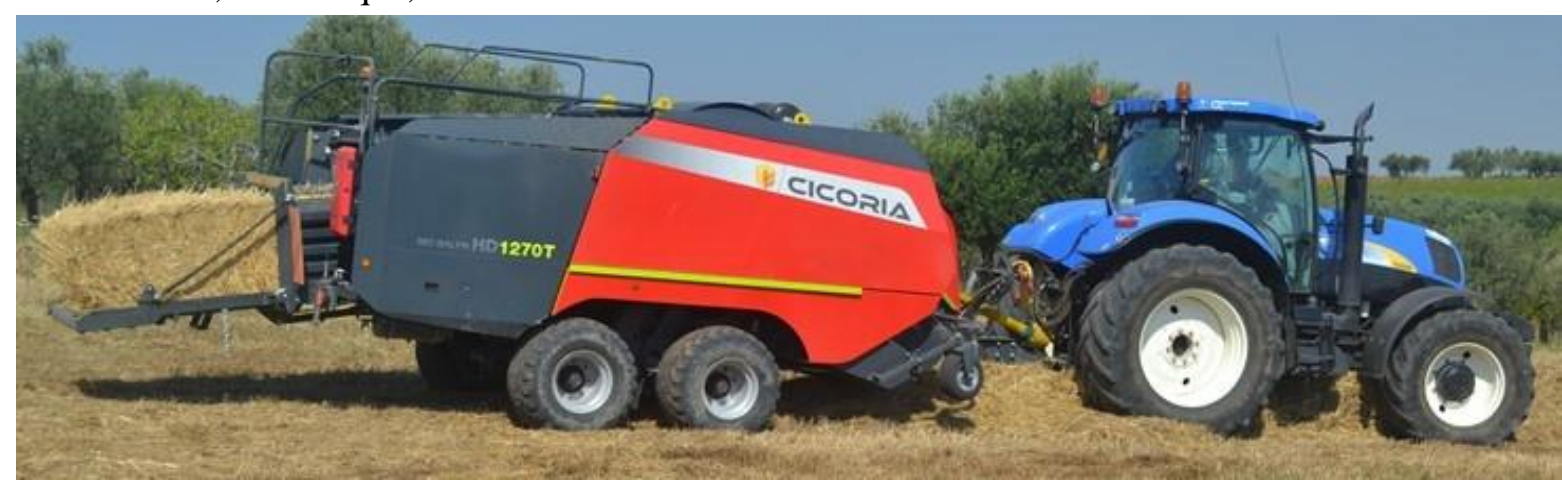

Fig 1. Big square baler Cicoria HD 1270T trailed by tractor New Holland 6090 during the tests

In detail, Figure 2a shows the machine operation during the bale forming. The motion from the tractor PTO through the Hooke's joints reaches the flywheel of the big baler and by this, therefore, the transmission for the piston operation. A suitable set of rods and rocker arms, each with its own inertia, transforms the rotary motion into the oscillatory motion of the piston (Fig. 2b).
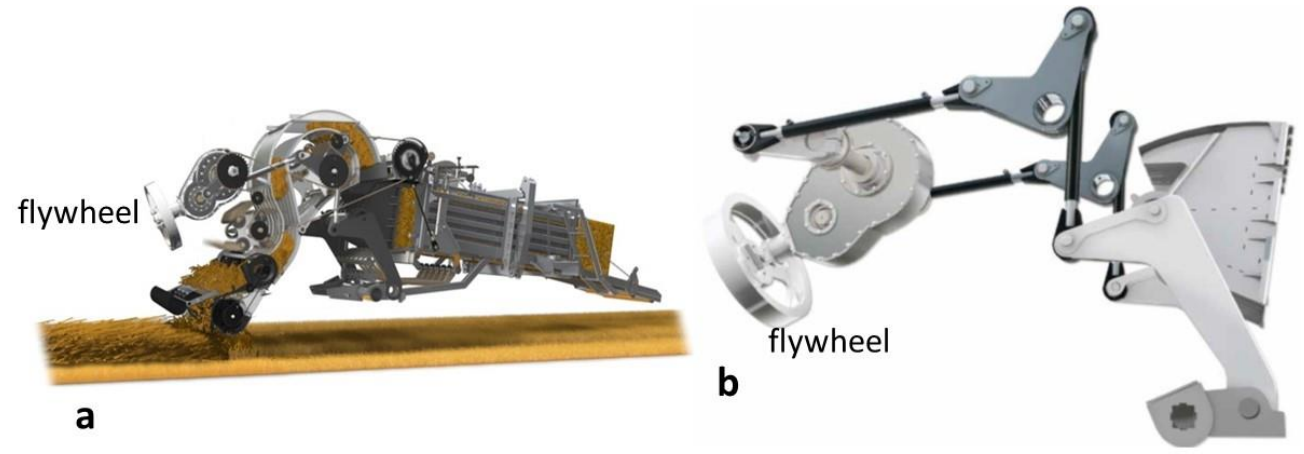

Fig. 2. Operation of the big baler aimed at the construction of square bales (a); transformation of the rotary motion into an oscillating motion of the piston (b)

The required power at PTO and the speed of the PTO itself were assessed through the contactless rotary torque transducer Datum Electronics PTO series 420 [15-18].

The main feature of this transducer is that it is able to measure the torque strain in the shaft via an on-shaft microprocessor circuit, which also assesses the shaft rotational speed. The torque and speed data are transmitted to the stationary part via a contactless method and are transmitted to the control unit [19-22]. The control unit has in turn a RS232 data connection to be linked to a laptop. An ad hoc software allows the display and logging of torque speed and power data. Other technical characteristics of this transducer are: spline configurations male/female 13/8"x6 spline; power rating, measures power $188 \mathrm{~kW}$ at $104.72 \mathrm{rad} \cdot \mathrm{s}^{-1}$; non-linearity $\pm 0.1 \% \mathrm{FSD}$; non-repeatability $\pm 0.05 \% \mathrm{FSD}$; sample rate from 1 to 100 samples $\cdot \mathrm{s}^{-1}$; output baud rate, $9600 \mathrm{baud}$; torque rating measures torque up to a maximum of $1800 \mathrm{Nm}$, operating range -35 to $-75^{\circ} \mathrm{C}$. 
The rotary torque transducer Datum Electronics PTO series 420 has been linked between the tractor PTO and the Hooke's joint, as shown in Fig. 3.

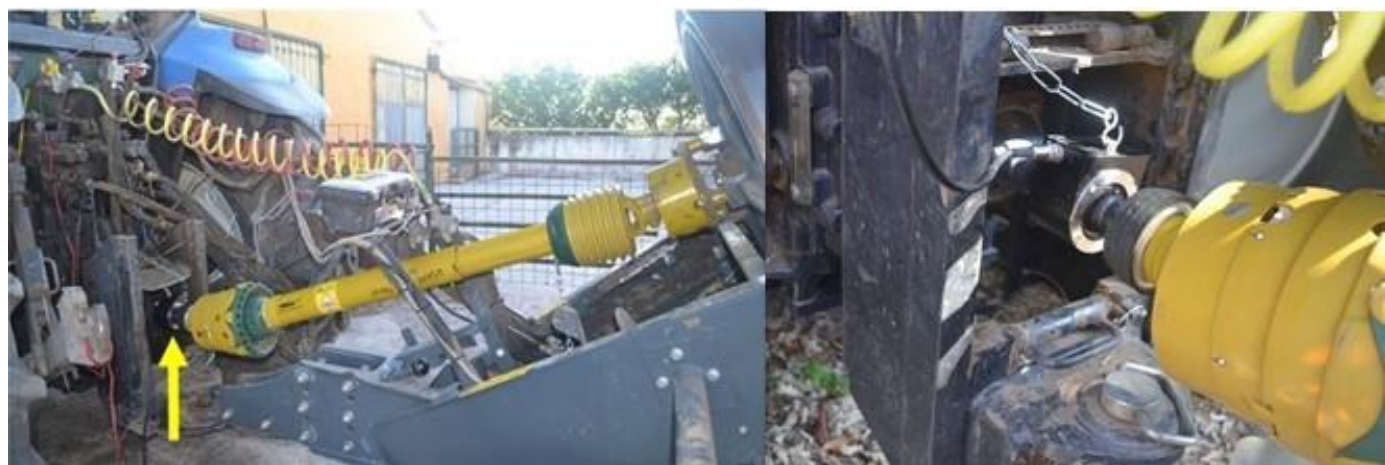

Fig. 3. Torque and speed transducer linked to the tractor PTO

The procedure used for field measurements using straw had the object to record the operative condition several times. The duration of data recording ranged within the interval 180-600 s, according to the path followed by the tractor.

The obtained data were consisted within the different carried out tests, so we further analysed only one of these complete data sets.

\section{Results and discussion}

The torque and the PTO angular speed as the function of the time history are reported in Fig. 4. These graphs, which highlight the patterns of the torque and the PTO angular speed, respectively, over the analysis period, allow a swift sight evaluation of both the torque and PTO speed fluctuations to be carried out. Recorded minimum and maximum values of PTO speeds and the required torque, as well as the corresponding averages and standard deviations are summarized in Table 1.

The tractor driver at instant $t=0$ engages the clutch to operate the PTO and then accelerates the tractor engine to reach the PTO angular speed of about $105.78 \mathrm{rad} \cdot \mathrm{s}^{-1}$, taking about $100 \mathrm{~s}$, mainly due to the high inertia of the driveline linked to the Cicoria's machine (Fig. 4).

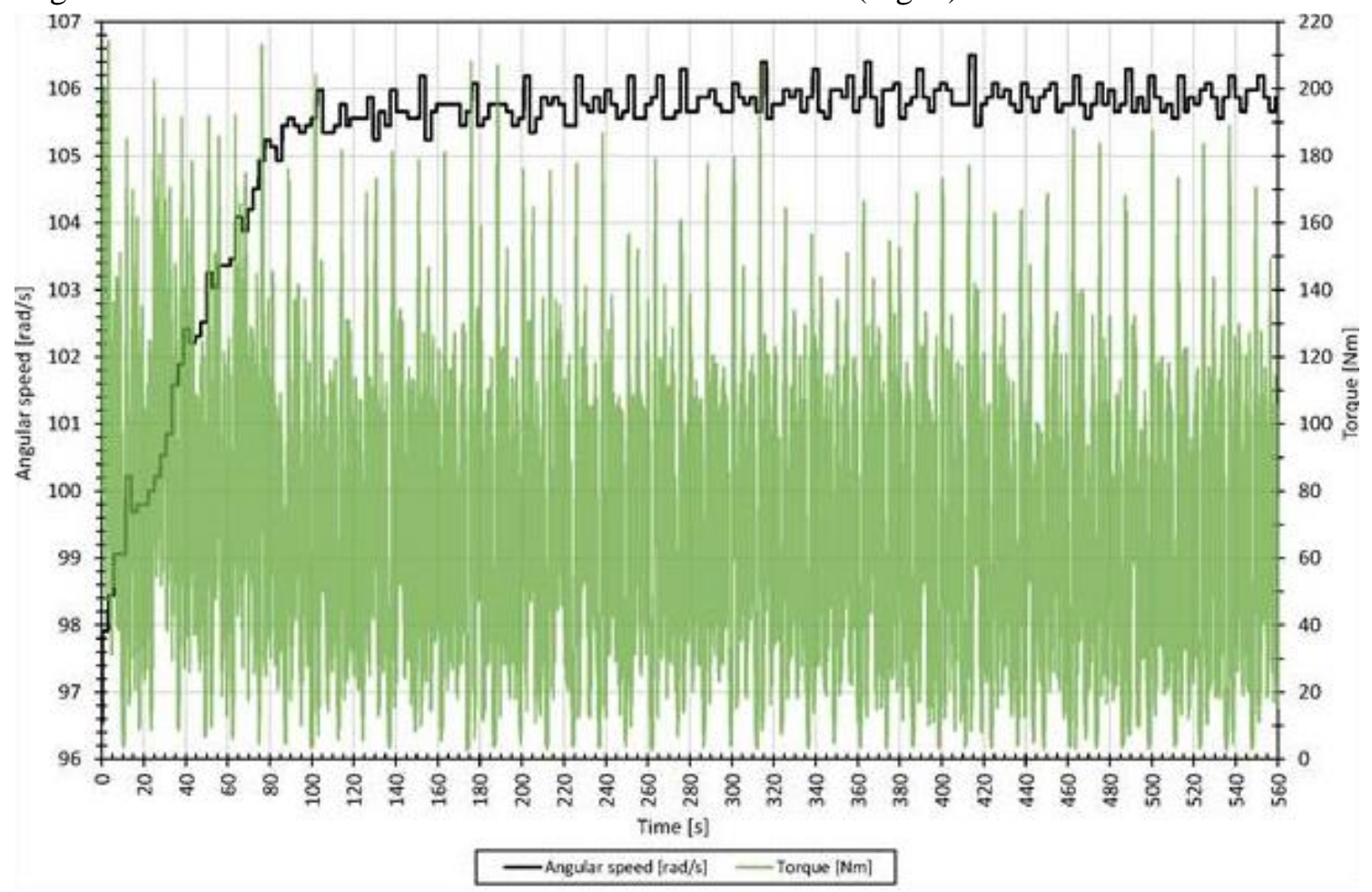

Fig. 4. Torque and PTO angular speed values vs Time 
Measured values concerning the PTO angular speed and required torque

\begin{tabular}{|c|c|c|c|c|}
\hline Property & Min & Max & Average & Standard deviation \\
\hline PTO $\left(\mathrm{rad} \cdot \mathrm{s}^{-1}\right)$ & 98.01 & 106.50 & 105.21 & 1.63 \\
\hline Torque $(\mathrm{N} \mathrm{m})$ & 2.64 & 214.41 & 69.25 & 40.94 \\
\hline
\end{tabular}

Fig. 5 reports the amplitude distribution of the torque, which supply a measure of the percentage time the torque occupies in each bandwidth of $5 \mathrm{~N} \mathrm{~m}$, over the range 0 to $215 \mathrm{~N} \mathrm{~m}$. The graph in the figure does not show a well-defined peak, but a series of peaks that denote a considerable fluctuation. This trend is confirmed by the torque standard deviation value shown in Table 1 . The analysed dataset has a skewness equal to 0.435 and this, as is known, means that the distribution will not be symmetrical and the right-hand tail is longer than the left-hand one, even if, in practical terms, the torque values greater than $125 \mathrm{~N} \mathrm{~m}$ have an amplitude distribution less than $2 \%$. Conversely, the kurtosis parameter of this distribution is -0.32 , which indicates a platykurtic distribution, that is there are fewer and less extreme outliers if compared with a normal distribution.

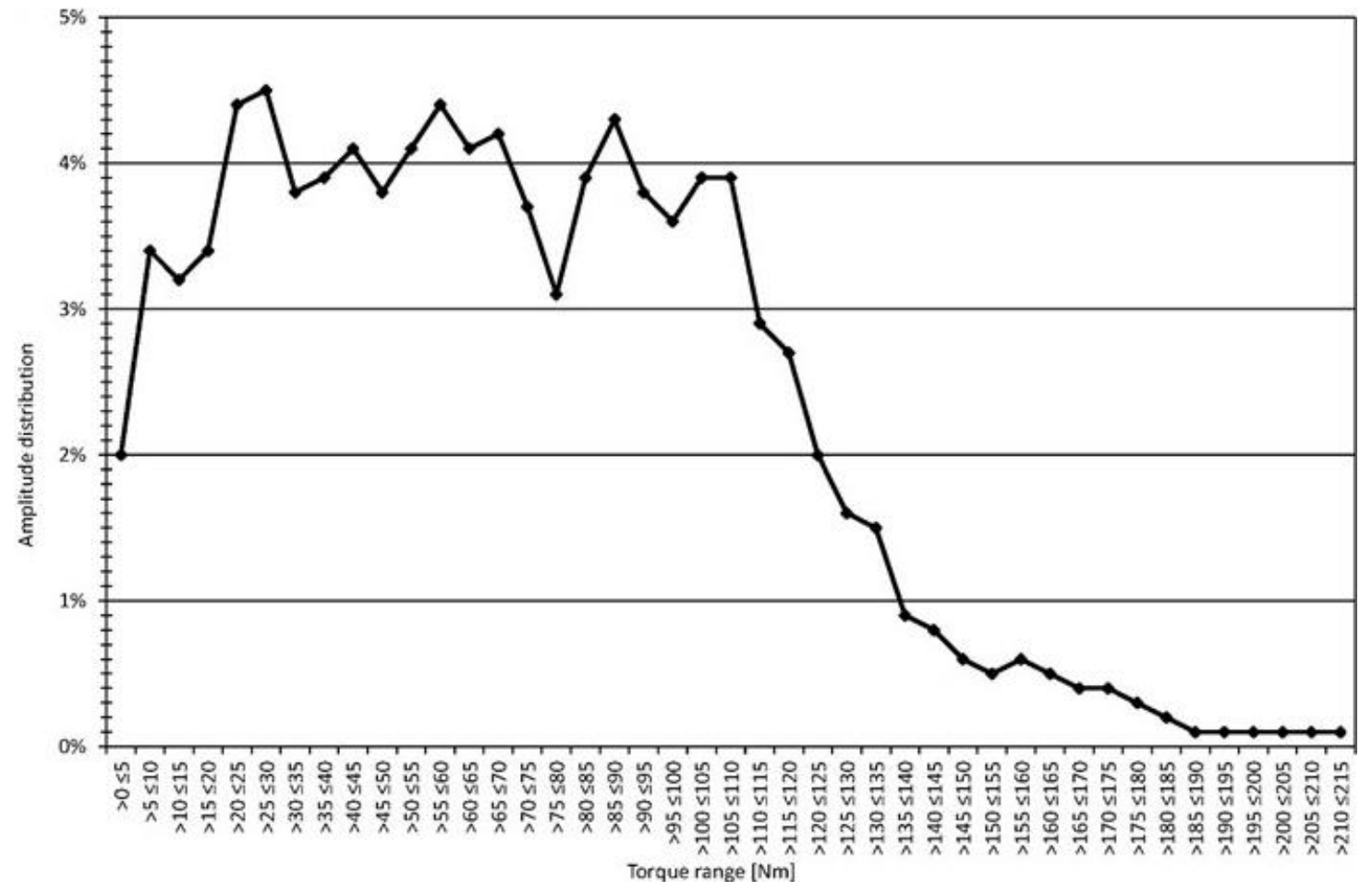

Fig. 5. Torque distribution in percentage of time for bandwidth over the measured range

This variability in stress could induce fatigue phenomena in the components that make up the piston motion transmission chain, with a reduction in their useful life. The studies reported in this paper were performed in the time domain. Further analyses in this regard would be needed to evaluate the natural frequencies of the components and the excitation frequencies corresponding to the stresses described.

\section{Conclusions}

1. During the tests carried out the Cicoria's machine required a maximum power of $25 \mathrm{~kW}$.

2. This value, in agreement with the technical characteristics declared by the manufacturer, is probably also to be attributed to the particular physical conditions of the straw used for bales packaging.

3. Based on these results, then, the manufacturer's suggestion to use tractors with a rated power of $60 \mathrm{~kW}$ seems to be right.

4. Further tests will be carried out in different operating conditions with particular regard to different physical state of both hay and straw.

\section{Acknowledgements}

The authors equally contributed to the present study. 


\section{References}

[1] Bell B. Farm. Machinery, 5th ed.; Old Pond Publishing: Ipswich, UK, 2008.

[2] Maraldi M., Molari L., Regazzi N., Molari G. Analysis of the parameters affecting the technical behaviour of straw bales under compression. Biosyst. Eng. Vol. 160, 2017, pp. 179-193

[3] Maguire S.M., Godwin R.J., O’Dogherty M.J., Blackburn K. A dynamic weighing system for determining individual square bale weights during harvesting. Biosyst. Eng. Vol. 98, 2007, pp. 138145.

[4] D’Alessandro F., Bianchi F., Baldinelli G., Rotil A., Schiavoni S. Straw bale constructions: Laboratory, in field and numerical assessment of energy and environmental performance. J. Build. Eng.Vol. 11, 2017, pp. 56-68.

[5] Maraldi M., Molari L., Molari G., Regazzi N. Time-dependent mechanical properties of straw bales for use in construction. Biosyst. Eng. Vol. 172, 2018, pp. 75-83.

[6] Dyjakon A. The influence of the use of windrowers in baler machinery on the energy balance during pruned biomass harvesting in the apple orchard. Energies. Vol. 11, 2018, 3236. DOI: $10.3390 /$ en11113236

[7] Redcay S., Koirala A., Liu J. Effects of roll and flail conditioning systems on mowing and baling of Miscanthus x giganteus feedstock. Biosystem Engineering. Vol. 172, 2018, pp. 134-143

[8] Cerruto, E.; Manetto, G.; Santoro, F.; Pascuzzi S. Operator Dermal Exposure to Pesticides in Tomato and Strawberry Greenhouses from Hand-Held Sprayers. Sustainability 2018, 10(7), 2273, DOI: $10.3390 \cdot \mathrm{s}^{-1} \mathrm{u} 10072273$

[9] Baldoin C., Balsari P., Cerruto E., Pascuzzi S., Raffaelli M. Improvement in pesticide application on greenhouse crops: Results of a survey about greenhouse structures in Italy. Acta Hort. vol. 801, 2008, pp. 609-614.

[10] Langer T.H., Ebbesen M.K., Kordestani A. Experimental analysis of occupational whole-body vibration exposure of agricultural tractor with large square baler. Int. J. Ind. Ergon. Vol. 47, 2015, pp. 79-83.

[11] Guerrieri A.S., Anifantis A.S., Santoro F., Pascuzzi S. Study of a Large Square Baler with Innovative Technological Systems that Optimize the Baling Effectiveness. Agriculture, Volume 9(5), 2019, 86 p. DOI: 10.3390/agriculture9050086

[12] Bulgakov V., Pascuzzi S., Anifantis A.S., Santoro F. Oscillations Analysis of Front-Mounted Beet Topper Machine for Biomass Harvesting. Energies, vol. 12(14), 2019, 2774 p. DOI: $10.3390 /$ en12142774

[13] Guzzomi A., Rondelli V. Narrow-track wheeled agricultural tractor parameter variation. Journal of Agricultural safety and Health 19(4), 2013, 237-260

[14] Kofoed S.S. An Automatic coupling device for tractor PTO drivelines. J. Agric. Eng. Res. Vol. 30, 1984, pp. 347-352. DOI:10.1016· $\mathrm{s}^{-1} 0021-8634(84) 80035-9$

[15] Crolla D.A. Torsional Vibration Analysis of tractor and machine PTO drivelines. J. Agric. Eng. Res. Vol. 23, 1978, pp.259-272

[16] Crolla D.A. Theoretical analysis of inertia torque overloads when starting up PTO driven machinery. J. Agric. Eng. Res. Vol. 22(2), 1977, 197 p.

[17] Bulgakov V., Pascuzzi S., Ivanovs S., Nadykto V., and Nowak J. Kinematic discrepancy between driving wheels evaluated for a modular traction device. Biosystems Engineering, 196,2020, pp. 8896. DOI: 10.1016/j.biosystemseng.2020.05.017

[18] Shim S.B., Park Y.J., Kim K.U. Reduction of PTO rattle noise of an agricultural tractor using an anti-backlash gear. Biosystems Engineering 100(3), 2008, pp. 346-354.

[19] Park Y.J., Kim S.C., Kim J.G. Analysis and verification of power transmission characteristics of the hydromechanical transmission for agricultural tractors. J. Mech Sci Technol 30, 2016, pp. 5063 5072. DOI: $10.1007 \cdot \mathrm{s}^{-1} 12206-016-1056-\mathrm{y}$

[20] Gomez K.A., Gomez A.A. Statistical Procedures for Agricultural Research, 2nd ed.; WileyInterscience: New York, NY, USA, 1984; ISBN 978-0471870920.

[21] Gibson, J. Non-linear Automatic Control. New York: McGraw Hill, 1963.

[22] Kumhála F., Kroulík M., Prošek V. development and evaluation of forage yield measure sensors in a mowing-conditioning machine. Computer and Electronics in Agriculture. Vol. 58, 2007, pp. 154163 